\title{
EDUCAÇÃO AMBIENTAL E SUSTENTABILIDADE: UMA PREOCUPAÇÃO NECESSÁRIA E CONTÍNUA NA ESCOLA
}

\author{
Katiane Pedrosa Mirandola Silva ${ }^{1}$ \\ Keliene Pedrosa Mirandola Silva² \\ Karine de Oliveira Canedo ${ }^{3}$ \\ Désirée Golçalves Raggi ${ }^{4}$ \\ José Geraldo Ferreira da Silva ${ }^{5}$
}

RESUMO: Nas últimas décadas a Educação Ambiental ganhou e ampliou sua relevância, especialmente na sensibilização e na conscientização de alunos. Educação Ambiental e Sustentabilidade são temas abordados, mas nem sempre presentes no currículo escolar, como prevê a legislação. Este estudo objetivou mostrar como ambos são incluídos no planejamento escolar, via análise do plano de ação de 2018, e, de entrevistas semiestruturadas feitas em duas escolas do sul do Espírito Santo, Brasil. Demonstrou necessidade de incluí-los e intensificálos de forma interdisciplinar, contínua e permanentemente. A escola é o espaço apropriado para mudanças, podendo gerar um futuro melhor e indivíduos críticos e conscientes, capazes de reduzir os efeitos que devastam o meio ambiente.

Palavras-chave: Educação Ambiental; Sustentabilidade; Interdisciplinar; Escola.

\footnotetext{
${ }^{1}$ Mestre em Gestão Social, Educação e Desenvolvimento Regional pela Faculdade Vale do Cricaré (ES). E-mail: katianepms@yahoo.com.br.

2 Mestre em Gestão Social, Educação e Desenvolvimento Regional pela Faculdade Vale do Cricaré (ES). E-mail: kelienepmsilva@gmail.com.

${ }^{3}$ Mestre em Gestão Social, Educação e Desenvolvimento Regional pela Faculdade Vale do Cricaré (ES). E-mail: karinecanedo@gmail.com.

${ }^{4}$ Doutora em Ciências da Educação pela Universidade del Norte, Paraguai (2008), professor pesquisador da Universidade Federal do Espírito Santo. E-mail: desireeraggi@yahoo.com.br.

5 Doutor em engenharia Agrícola pela Universidade Federal de Viçosa (1999), Docente da Faculdade Vale do Cricaré e pesquisador do Instituto Capixaba de Pesquisa Assistência Técnica e Extensão Rural. E-mail: jgeraldo@incaper.es.gov.br. 


\section{Introdução}

A Educação Ambiental é um tema que deve ser abordado no currículo escolar desde os anos iniciais até os cursos superiores, pois o estímulo e o desenvolvimento de ações voltadas para esse tema geram contribuições significativas para produzir uma sociedade mais consciente, uma vez que ações baseadas nos princípios definidos pela Política Nacional de Educação Ambiental (PNEA), favorecem a formação de sujeitos participativos e com senso de responsabilidade.

Segundo Dias (1992, p. 31):

A Educação Ambiental é a dimensão da educação formal que se orienta para a resolução dos problemas concretos do meio ambiente através [sic] de enfoques interdisciplinares, e de uma participação ativa e responsável de cada indivíduo e da coletividade.

Nessa perspectiva, a Educação Ambiental pode contribuir significativamente para aperfeiçoar a relação entre a sociedade e o ambiente, porém, esta deve ter um enfoque voltado para a participação ativa e prazerosa.

A presença, em todas as práticas educativas, da reflexão sobre as relações dos seres entre si, do ser humano com ele mesmo e do ser humano com seus semelhantes é condição imprescindível para que a Educação Ambiental ocorra (VASCONCELLOS, 1997). A Educação Ambiental deve ir além dos problemas ambientais, visando uma formação voltada ao exercício da cidadania e da formação de valores.

Com essa visão, e, por acreditar na construção da cidadania e da consciência ambiental na escola, este estudo teve como objetivo investigar se os temas Educação Ambiental e Sustentabilidade vêm sendo inseridos tanto no planejamento quanto no currículo escolar de maneira contínua e interdisciplinar. Almejou responder a seguinte problemática: A Educação Ambiental e a Sustentabilidade têm sido incluídos de forma interdisciplinar e contínua no planejamento e no currículo de duas escolas do sul do estado do Espírito Santo, Brasil? Para respondê-la, foi necessário analisar o plano de ação e foram realizadas entrevistas semiestruturadas com pedagogos e gestores.

Procurou-se, então, averiguar se as ações relacionadas à Educação Ambiental e à Sustentabilidade traçadas no plano de ação anual das escolas são executadas, de forma contínua e interdisciplinar, em todos os níveis escolares, inclusive no planejamento diário dos professores.

\section{A Educação Ambiental como prática curricular contínua na escola}

A Educação Ambiental surge como instrumento fundamental à transformação das pessoas. De acordo com a Política Nacional de Educação Ambiental, Lei Federal no 9.795/99, entende-se Educação Ambiental (EA) como: 
Um conjunto de processos por meio dos quais o indivíduo e a coletividade constroem valores sociais, conhecimentos, habilidades e competências voltadas para a conservação do meio ambiente, bem de uso comum e do povo, essencial à ótima qualidade de vida e sua sustentabilidade (BRASIL, 1999, p.1).

A Educação Ambiental deve fazer parte continuamente das ações curriculares. Para isso, é preciso respeitar os princípios e os objetivos da Lei no 9.795/1999, que institui a Política Nacional de Educação Ambiental e orienta as metodologias adequadas para ensinar a temática ambiental no contexto escolar. Os Parâmetros Curriculares Nacionais (PCNs) estabelecem que a educação é vista como elemento indispensável para a transformação da consciência ambiental, e, portanto, novas posturas e novos pontos de vistas devem ser adotados (BRASIL, 1998).

Ao buscar sensibilizar os alunos acerca da importância do meio ambiente e de sua preservação, a escola estimula ideias e atitudes que podem contribuir para um futuro mais benéfico para as gerações vindouras. Nesse sentido, ressalta Sato (2002), a Educação Ambiental sustenta todas as atividades e impulsiona os aspectos físicos, biológicos e culturais dos seres humanos.

Importante observar que a Educação Ambiental não deve ser tratada apenas como um conteúdo escolar ou uma disciplina, mas sim de forma interdisciplinar, integrando diversas áreas do saber. Nessa perspectiva, os temas geradores ou transversais quando apresentados em forma de projetos, por exemplo, tendem a envolver aspectos diversos em uma múltipla rede de conhecimentos que explora fatores políticos, econômicos, culturais e científicos.

Além disso, as escolas são espaços privilegiados para a implementação de atividades que propiciem reflexões e que despertem nos alunos a autoconfiança e a responsabilidade para com a proteção ambiental. Isso se dá, quando a escola é capaz de aprofundar conhecimentos sobre a relação entre o ser humano e a natureza usando ações de preservação, conservação e administração de seus recursos.

"A natureza é um grande patrimônio da sociedade. Consequentemente, a Educação Ambiental se torna uma prática social, com a preocupação da preservação dessa sua riqueza" (VARINE, 2000, p.62). A Educação Ambiental contribui para que relação do ser humano com a natureza se torne um processo permanente e necessário no qual se adquirem os conhecimentos e as experiências para que haja a participação dos cidadãos na solução dos problemas ambientais.

É preciso que a escola se reconheça como peça fundamental no sentido de conscientizar os alunos para fazê-los compreender que todos nós, enquanto indivíduos, temos garantido o direito a um meio ambiente que seja saudável. E, sendo assim, também temos o dever moral, ético e político de mantê-lo preservado tanto para as gerações atuais quanto para as próximas (SEGURA, 2001).

revista brasileira educação ambiental 
O desafio para quem deseja realizar a Educação Ambiental é o da sensibilização, da mobilização do grupo para o enfrentamento e a solução de problemas, é a criação de situações, jogos, simulações que nos possibilitem exercitar a nossa capacidade de trabalho interdisciplinar e intersaberes, construindo conhecimentos e procedimentos que nos preparam para a tomada de decisões sobre os impasses com que nos deparamos enquanto espécie humana e enquanto indivíduos (SORRENTINO, 1995).

Diante desse contexto, cabe à escola promover a cidadania e o respeito ao meio ambiente, formando sujeitos com uma visão crítica e global, plenos de atitudes e comprometidos com a proteção, a preservação e a conservação do meio em que vivem.

\section{Educar para uma vida sustentável: práticas escolares contínuas e permanentes}

O relatório Brundtlandt, também denominado de Nosso Futuro Comum, produzido pela comissão da Organização das Nações Unidas (ONU) denominada World Comission on Environment and Developmen caracteriza o desenvolvimento sustentável como aquele "[...] que atende às necessidades do presente sem comprometer a possibilidade de as gerações futuras atenderem as suas próprias necessidades" (CMMAD, 1991, p.46).

O relatório aponta ainda para a incompatibilidade entre desenvolvimento sustentável e os padrões de produção e consumo, trazendo à tona mais uma vez a necessidade de uma nova relação "ser humano-meio ambiente" e coloca ênfase na questão ética, que estende os benefícios de usufruir dos recursos naturais para todos os seres humanos, independente de nacionalidade, da classe social e do momento em que vive, seja hoje ou no futuro (CMMAD, 1991).

O conceito de desenvolvimento sustentável pressupõe, entre outros aspectos, uma educação integral, ou seja, aquela que não se restringe aos conhecimentos científicos (de física, matemática, química, biologia, ou línguas etc.), mas abarca a formação de valores humanos. Assim, uma educação voltada para a sustentabilidade (desenvolvimento sustentável), ao reconhecer as necessidades das gerações futuras, deve estar preocupada com mudanças de hábitos e práticas sustentáveis que contribuem para uma tomada de consciência, e, de ações concretas nas relações ser humano e natureza, em busca do equilíbrio ambiental.

A sustentabilidade é um processo que deve ser constituído em longo prazo, pois exige mudança de consciência e de estilo de vida de uma sociedade. Logo, interfere diretamente nos hábitos de consumo. Partindo desse pressuposto, Leff $(2001$, p. 31) ressalta que:

O princípio de sustentabilidade surge como uma resposta à fratura da razão modernizadora e como uma condição para construir uma nova racionalidade produtiva, fundada no potencial ecológico e em novos sentidos de civilização a partir 
da diversidade cultural do gênero humano. Trata-se da reapropriação da natureza e da invenção do mundo. Não só de um mundo no qual caibam muitos mundos, mas de um mundo conformado por uma diversidade de mundos, abrindo o cerco da ordem econômica-ecológica globalizada.

Mudar estilos de vida implica na adoção de novas atitudes do dia a dia doméstico e nos espaços sociais (trabalho, escola, lazer). Todavia, tais mudanças devem ser antecedidas pela conscientização, pois não se adotam hábitos fortemente arraigados. Separar o lixo doméstico, economizar água, reduzir o consumo de plásticos são atitudes que não são facilmente adquiridas, sem que os sujeitos sejam dotados de uma nova consciência. Com isso, as ações referentes ao meio ambiente devem estar em consonância com os novos valores de ver e de viver no mundo, especialmente, com o modo de produzir e consumir, e também os novos padrões comportamentais vinculados à sustentabilidade.

Para Costa e Gonçalves (2004) a escola é o lugar privilegiado para aprendizagens, por ser um espaço em que se adquirem valores, atitudes e comportamentos em benefício do meio ambiente, podendo, assim, utilizar o instrumento da sensibilização como forma de construção de novos hábitos favoráveis ao meio ambiente.

Nos PCNs, além das disciplinas consideradas fundamentais para o conhecimento dos saberes acumulados socialmente, foram inseridas questões urgentes, que devem necessariamente ser tratadas de maneira transversa, sendo o Meio Ambiente um dos temas transversais. Esse tema tem como função principal "a contribuição para a formação de cidadãos conscientes, aptos para decidirem e atuarem na realidade socioambiental de um modo comprometido com a vida, com o bem-estar de cada um e da sociedade, local e global" (BRASIL, 1997, p.11).

Torna-se, então, importante a escola realizar práticas curriculares que englobem a Educação Ambiental e a Sustentabilidade de forma interdisciplinar e transversal. $O$ processo interdisciplinar é aquele no qual duas ou mais disciplinas são expressas por meio de inter-relações (CARVALHO, 1998). A integração entre as diferentes disciplinas promove a melhor abordagem de um tema relevante para determinada comunidade. A Lei o 9.795/99 determina que a Educação Ambiental se concretize fundamentada em princípios como o pluralismo de ideias e concepções pedagógicas, na perspectiva da inter, multi e transdisciplinaridade (BRASIL, 1999). Portanto, deve ser dialógica e democrática.

$\mathrm{Na}$ escola, os alunos mantêm contato direto com seus professores. É nesse espaço que as atividades voltadas à sensibilização ambiental podem ser amplamente empregadas por meio de reflexões acerca de problemas e de práticas ambientais inerentes à região em que vivem. Dessa forma, a escola promove a "vinculação entre a ética, a educação, o trabalho e as práticas sociais", respeitando o IV princípio básico da Lei no 9.795/99 (BRASIL,1999).

Ao evidenciar os problemas ambientais presentes na comunidade, como a degradação do solo, o uso abusivo da água, o desmatamento, incluindo-se 
também aí a desigualdade social, torna-se emergente 0 tema da Sustentabilidade na prática escolar, com o intuito de contribuir para que os alunos reconheçam sua realidade, ou, quem sabe até, possam minimizar os problemas e as questões de natureza ambiental.

Essa sensibilização precisa ser contínua e deve fundamentar-se em ações discutidas desde o planejamento coletivo do Projeto Político-Pedagógico (PPP) da escola, até nos planos diários dos professores. Assim, pode-se planejar projetos, palestras, seminários e outros eventos que enfatizem, de forma consciente e eficaz, as soluções que irão minimizar os problemas ambientais. No entanto, deve-se ter em conta que, dar enfoque às questões ambientais apenas em datas comemorativas implica em ferir um dos princípios básicos da Política Nacional de Educação Ambiental (Item V, Art. 4ํㅜ) que trata da continuidade e permanência desses estudos (BRASIL, 1999).

Gadotti (2008, p. 75), destaca que educar para a sustentabilidade implica em mudanças no sistema e no respeito à vida, no "[...] cuidado diário com o planeta e cuidado com toda a comunidade da vida, da qual a vida é um capítulo". Sendo assim, o autor idealiza a educação para a sustentabilidade, como educação para a vida, pois ambas não são dissociadas. A sustentabilidade está relacionada ao sonho de viver bem, em que se consubstancia uma dinâmica equilibrada entre ser humano e ambiente.

No artigo $2^{\circ}$ da PNEA, a Educação Ambiental é considerada como direito de todos e componente essencial da educação nacional, devendo estar presente, de forma articulada, em todos os níveis e modalidades do processo educativo.

Para isso, é necessário que os educadores tenham condições de trabalhar a Educação Ambiental por meio de materiais didáticos, guias curriculares e projetos apropriados que estimulem reflexões acerca das questões ambientais e da construção de uma consciência crítica.

Considerando essa perspectiva, foi feita uma pesquisa em duas escolas municipais do sul do Espírito Santo/Brasil pertencentes à rede pública de ensino: a Escola Municipal A, localizada em Presidente Kennedy, que atende alunos da Educação Infantil, do Ensino Fundamental e da Educação de Jovens e Adultos (EJA), e a Escola Municipal B, localizada em Marataízes, que atende alunos da Educação Infantil e do Ensino Fundamental ${ }^{6}$.

Para a coleta de dados foram realizadas entrevistas semiestruturadas, contendo como base um roteiro com questões objetivas e subjetivas, elaboradas a partir do objetivo da pesquisa. Seguindo os conceitos de Gil (2017), foi realizada "entrevista aberta" (com questões e sequência predeterminadas, mas com ampla liberdade para responder), sendo essas com dois gestores e quatro pedagogos das duas instituições mencionadas. Também foram analisados os

${ }^{6}$ As escolas que fizeram parte dessa pesquisa não tiveram seus nomes divulgados, por isso receberam nomes fictícios: Escola Municipal A e Escola Municipal B.

Revbea, São Paulo, V. 14, No 1: 69-80, 2019. 
Planos de Ação do ano de 2018 de cada escola para investigar como essas instituições contemplam os temas Educação Ambiental e Sustentabilidade.

\section{Análise do plano de ação das escolas}

A Escola Municipal A atende cerca de 800 alunos, em média, da Educação Infantil, do Ensino Fundamental e da EJA, contemplando outras vinte e uma comunidades vizinhas além da localidade em que está situada.

Em seu Plano de Ação de 2018, os temas Educação Ambiental e Sustentabilidade são contemplados nos períodos apontados na Tabela 1.

Tabela 1: Ações do Plano Anual da Escola Municipal A

\begin{tabular}{|c|c|}
\hline MESES & $\begin{array}{c}\text { AÇÕES REFERENTES AOS TEMAS “EDUCAÇÃO AMBIENTAL E } \\
\text { SUSTENTABILIDADE” }\end{array}$ \\
\hline MARÇO & $\begin{array}{r}\text { Palestra sobre a importância da preservação da água, da reciclagem } \\
\text { do lixo e do plantio de árvores. }\end{array}$ \\
\hline JULHO & Programa Agrinho: Trabalho e consumo \\
\hline AGOSTO & Projeto: Sustentabilidade - Feira Tecnológica \\
\hline
\end{tabular}

Fonte: Autores, 2018.

De acordo com a Tabela 1, essa escola apresenta em seu Plano de Ação, poucas ações voltadas para os temas em foco.

Já a Escola Municipal B atende aproximadamente 300 alunos, da Educação Infantil ao Ensino Fundamental, contemplando cinco comunidades vizinhas.

Em seu Plano de Ação de 2018, os temas: Educação Ambiental e Sustentabilidade estão ou estarão presentes nos seguintes períodos do ano letivo:

Tabela 2: Ações do Plano Anual da Escola Municipal B

\begin{tabular}{|c|l|}
\hline MESES & \multicolumn{1}{|c|}{$\begin{array}{c}\text { AÇÕES REFERENTES AOS TEMAS “EDUCAÇÃO AMBIENTAL E } \\
\text { SUSTENTABILIDADE" }\end{array}$} \\
\hline MARÇO & Palestra: "Vamos cuidar do Brasil, cuidando das águas". \\
\hline ABRIL & $\begin{array}{l}\text { Palestra: "Preservação do meio ambiente, não poluindo as águas com o } \\
\text { lixo doméstico" (Secretaria do Meio Ambiente). }\end{array}$ \\
\hline MAIO & $\begin{array}{l}\text { Ação da Conferência "Vamos cuidar do Brasil, cuidando das águas": Aula } \\
\text { de Campo }\end{array}$ \\
\hline JUNHO & $\begin{array}{l}\text { Ação da Conferência "Vamos cuidar do Brasil, cuidando das águas": } \\
\text { Realização de passeata. }\end{array}$ \\
\hline JULHO & $\begin{array}{l}\text { Ação da Conferência "Vamos cuidar do Brasil, cuidando das águas": } \\
\text { Coleta de materiais recicláveis pelos alunos. }\end{array}$ \\
\hline AGOSTO & $\begin{array}{l}\text { Ação da Conferência "Vamos cuidar do Brasil, cuidando das águas": } \\
\text { Palestra sobre a conservação dos recursos naturais. }\end{array}$ \\
\hline SETEMBRO & $\begin{array}{l}\text { Ação da Conferência "Vamos cuidar do Brasil, cuidando das águas": } \\
\text { Mostra Cultural sobre as boas práticas de conservação dos mananciais } \\
\text { da comunidade "Boa Vista do Sul". }\end{array}$ \\
\hline
\end{tabular}

Fonte: Autores, 2018.

Revbea, São Paulo, V. 14, № 1: 69-80, 2019.

revista brasileira 
De acordo com a Tabela 2, a escola B realiza, em sintonia com seu plano de ação anual, várias ações abordando os temas em foco, e em vários períodos correntes do ano.

Observa-se também que a escola $B$ propõe mais ações voltadas aos temas Educação Ambiental e Sustentabilidade do que a escola $A$, no ano letivo de 2018. Estas foram realizadas de maneira a transpor saberes por meio de ações direcionadas para a sensibilização e a preservação do meio ambiente, contando com participação efetiva da escola (profissionais da educação e alunos), e também em parceria com outras secretarias municipais.

Para Ferreira (2011), a Educação Ambiental é uma proposta que desenvolve no ser humano, conhecimento, habilidades e atitudes, direcionadas para a preservação do meio ambiente. $E$ a escola deve estar preparada para oferecer e proporcionar um ensino participativo que contribua para a construção de um conhecimento sustentável, o qual pode e deve ser compartilhado com toda a sociedade.

\section{A visão dos entrevistados a respeito dos temas: Educação Ambiental e Sustentabilidade}

Em um primeiro momento os pedagogos foram questionados sobre seus conhecimentos acerca do conceito de "Sustentabilidade". Eles relacionaram este tema às atividades humanas no suprimento de suas necessidades, sem agredir o meio ambiente e destacaram a importância de criar mecanismos que proporcionem melhorias nas localidades, por meio de ações diversas. Demonstraram que se apropriaram desse conceito. Além disso, consideram a importância de se abordar tais assuntos na escola, de forma contínua, pois os alunos precisam entender a necessidade de cuidar e preparar o lugar em que vivem para garantir um futuro melhor para as futuras gerações. Mencionaram a necessidade de não apenas "fazer projetos e esquecê-los, mas pôr em prática essas ações".

No que se refere a cursos na área, declararam ter participado de cursos de capacitação e/ou aperfeiçoamento na área de Educação Ambiental, mas, segundo eles, esses temas não são abordados, em sua maioria, em todas as etapas de ensino pelas quais passam os alunos. Contudo, quando abordados no currículo e nos planejamentos, afirmaram que são conhecimentos significativos que influenciam possíveis mudanças de comportamento e que contribuem, assim, para um futuro mais consciente em relação ao meio ambiente.

É fundamental a escola ressaltar as possíveis abordagens da Educação Ambiental e da Sustentabilidade no processo diário do ensino, pois o educador, que já é um formador de opiniões, poderá compartilhar por meio de metodologias diversificadas a fim de que os alunos compreendam a importância da preservação do meio ambiente.

$\mathrm{Na}$ percepção dos gestores, a Educação Ambiental é um processo educacional responsável por formar cidadãos atentos com os problemas do meio 
ambiente e direcionados para a preservação dos recursos naturais. Essa educação precisa perpassar por uma ação permanente, pela qual toda a sociedade e a comunidade escolar tomam consciência da realidade existente e da importância global desse tema, mantendo, assim, uma relação harmoniosa com a natureza, visando preservar o meio ambiente.

Os gestores demonstraram ter conhecimentos do tema pesquisado e, no que se refere à importância de abordar de forma contínua os temas "Educação Ambiental e Sustentabilidade" na escola, afirmaram que são relevantes, devendo ser tratados com a devida importância, bem como é preciso inserir todos nessa discussão e nesse estudo. A finalidade deve ser promover e estimular a conscientização e a mobilização da sociedade acerca da necessidade de implantar um estilo de vida sustentável.

Com relação a abordagem desses temas em sala de aula, obteve-se as seguintes afirmações:

O gestor da escola $A$, afirmou que são abordados, porém com mais frequência na Educação Infantil e no Ensino Fundamental. Já o gestor da escola $\mathrm{B}$, afirmou que é abordado com mais frequência no Ensino Fundamental. Pelo exposto, é possível inferir que esses temas não são abordados de forma contínua em todas as etapas de ensino.

Sobre a frequência da abordagem desses temas, representada pela Figura 1, a mesma retrata graficamente como isso ocorreu em cada escola.

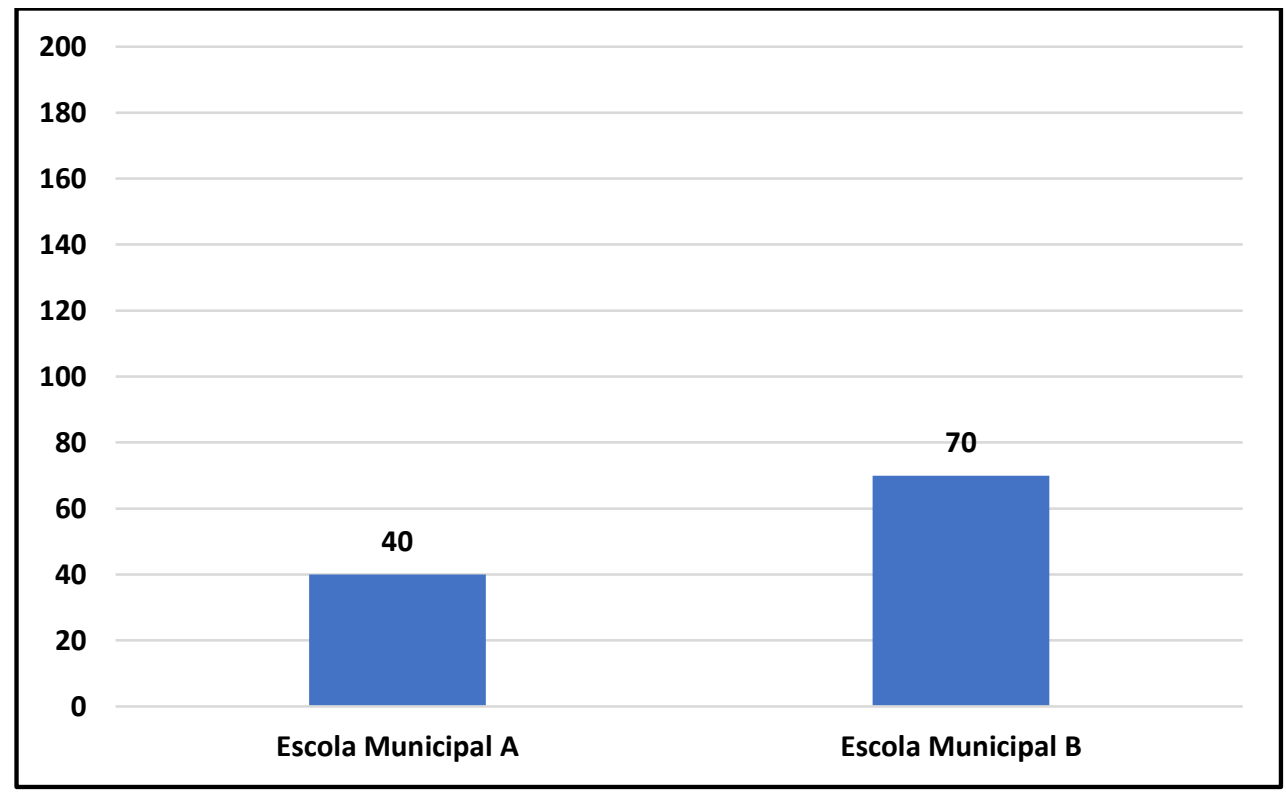

Figura 1: Gráfico sobre a abordagem dos temas "Educação Ambiental e Sustentabilidade" em dias letivos. Fonte: Autores, 2018. 
Segundo o gestor da Escola Municipal A, essa abordagem acontece em torno de $20 \%$ dos dias letivos. Já para o gestor da Escola Municipal B, acontece um pouco acima de $30 \%$ dos dias letivos.

De acordo com as percepções desses gestores, verificou-se que esses temas são abordados poucas vezes no decorrer do ano letivo, e essa abordagem ocorre com mais intensidade em ações direcionadas para públicos específicos e, raramente, é feita de forma interdisciplinar.

No que se refere à realização de ações voltadas para esses temas, até o mês de maio de 2018, a escola tem participado do projeto "Vamos cuidar do Brasil, cuidando das águas", com ações específicas para promover a ciência da sustentabilidade.

Uma palestra, com os pontos acima citados, foi realizada na escola B e ofertada para todos os alunos pela Secretaria Municipal de Meio Ambiente.

Essas ações praticadas nas escolas que envolvem diretamente os alunos são mecanismos muito propícios para sensibilizar a respeito do meio ambiente, pois, segundo Dias (1993), a aprendizagem será mais significativa se a atividade estiver integrada concretamente às situações do dia a dia do aluno e do professor. É preciso haver um planejamento coletivo, os alunos e a comunidade devem decidir, dialogar e participar de uma forma mais ativa no processo educativo

Para o gestor da escola $A$, também foram realizadas ações voltadas à Educação Ambiental, como uma palestra informativa para alunos e professores.

A palestra ofertada aos alunos da EJA, neste ano de 2018, em parceria com a Secretaria do Meio Ambiente, abordou a importância da preservação da água, da reciclagem do lixo e do plantio de árvores. Após a palestra os alunos receberam mudas para cultivar o plantio de novas árvores.

Pelo exposto, verificou-se que tanto a Educação Ambiental quanto a Sustentabilidade são temas presentes na escola e são trabalhados por meio de ações que contemplam uma maioria dos alunos, em períodos distintos. Contudo, ainda são temas que não são abordados de forma contínua e poucas foram as ações que contemplaram o planejamento diário do professor.

Em suma, apesar de serem temas importantes e relevantes do meio educacional, ainda é preciso trabalhar muito para contemplá-los de forma permanente em todas as etapas de ensino, visto que a realidade ainda está longe de ser a ideal. Todavia, é imprescindível utilizar adequadamente essa ferramenta disponível, a educação, com o intuito de sensibilizar e promover mudanças em nosso dia a dia. 


\section{Considerações Finais}

O estudo revelou que a Educação Ambiental deve favorecer a gestão sustentável de recursos naturais e consolidar o processo de ensino aprendizagem, ao mesmo tempo em que adentra a escola de forma contínua ou interdisciplinar.

Ao considerar que a Educação Ambiental é o instrumento, ou seja, uma ferramenta disponível às escolas para proporcionar reflexões, sensibilização e conscientização acerca da preservação do meio ambiente, com o intuito de contribuir para um futuro melhor, é imprescindível, também, promover grandes mudanças para que ações contínuas que contemplam o planejamento escolar permaneçam sendo realizadas.

De acordo com os resultados obtidos nas duas escolas da rede pública pesquisadas, constatou-se que a Educação Ambiental e a Sustentabilidade são temas abordados durante o ano letivo. Na escola $\mathrm{B}, \mathrm{com}$ a análise do plano de ação, emergiram várias ações direcionadas para o meio ambiente, permitindo aos seus educandos uma sensibilização diante dos problemas e das práticas ambientais locais. No entanto, elas não contemplam todas as etapas de ensino. Já na escola $A$ as ações são realizadas ao longo do ano letivo, mas de forma intercalada e para algumas etapas de ensino. Isso leva o educando a refletir em um determinado momento, e, posteriormente, ser conduzido ao esquecimento ao longo dos dias, no que deveria ser uma prática permanente.

A escola deve estimular nos educandos a consciência de que suas atitudes são importantes para o meio ambiente, sensibilizando-os continuamente por meio da Educação Ambiental os efeitos danosos que as inúmeras ações humanas podem causar a esse meio ambiente.

Diante do exposto, para modificar essa realidade, é necessário trabalhar de uma forma eficaz a Educação Ambiental no espaço escolar como um mecanismo duradouro e transformador, que pretende aperfeiçoar a conexão do homem com a natureza por meio de um desenvolvimento sustentável. Deve, com isso, contribuir para promover e propiciar um futuro melhor, formando, assim, indivíduos críticos, conscientes e participativos, que reduzem ao máximo, os impactos que danificam o meio ambiente.

\section{Referências}

BRASIL. Lei o 9.795, de 27 de abril de 1999. Política Nacional de Educação Ambiental. Diário Oficial da República Federativa do Brasil. Brasília, 28 de abril de 1999. Seção I. p. 1-3. Disponível em: <http://www.planalto.gov.br/ ccivil 03/leis/l9795.htm>. Acesso em: 15 set. 2018.

BRASIL, Ministério da Educação e Cultura. Secretaria da Educação Fundamental. Parâmetros curriculares nacionais: meio ambiente e saúde. Brasília, DF, 1998 (Temas transversais, 9). 
BRASIL. Parâmetros Curriculares Nacionais - apresentação dos temas transversais: ciências naturais. Ministério da Educação Fundamental. Brasília: MEC/ SEF, 1997.

CARVALHO, I.C.M. Em direção ao mundo da vida: interdisciplinaridade e Educação Ambiental: conceitos para se fazer Educação Ambiental. Brasília, DF: Instituto de Pesquisas Ecológicas, 1998.

COMISSÃO MUNDIAL SOBRE MEIO AMBIENTE E DESENVOLVIMENTO CMMAD - Nosso Futuro Comum. Rio de Janeiro: Fundação Getúlio Vargas, 1991.

COSTA, S.B.; GONÇALVES, A.B. Educação Ambiental e Cidadania: os desafios da escola de hoje. Atlas dos ateliers do $\bigvee$ o Congresso Português de Sociologia, 2004.

DIAS, G.F. Educação Ambiental: princípios e práticas. 2. Ed. São Paulo: Gaia, 1993.

DIAS, G.F. Educação Ambiental: princípios e práticas. São Paulo: Editora Gaia, 1992.

FERREIRA, L.J.C. Educação Ambiental: abordagens no ensino fundamental. Monografia. (Graduação em Ciências Biológicas). Faculdade Patos de Minas, Patos de Minas, 2011.

GADOTTI, M. Educar para a sustentabilidade. São Paulo: Instituto Paulo Freire, 2008.

GIL, A.C. Como elaborar projetos de pesquisa. 6 ed. São Paulo: Atlas, 2017.

LEFF. E. Saber ambiental: sustentabilidade, racionalidade, complexidade, poder. Petrópolis: Vozes, 2001.

SATO, M. Educação Ambiental. São Carlos: Rima, 2002.

SEGURA, D.S.B. Educação Ambiental na escola pública: da curiosidade ingênua à consciência crítica. São Paulo: Annablume: FAPESP, 2001.

SORRENTINO, M. Educação Ambiental e a Universidade um Estudo de Caso. Tese de Doutorado U.F.S.C. São Paulo:1995.

VASCONCELLOS, H.S.R. A pesquisa-ação em projetos de Educação Ambiental. In: PEDRINI, A. G. (org.) Educação Ambiental: reflexões e práticas contemporâneas. Petrópolis: Vozes, 1997.

VARINE, H. O Ecomuseu. Ciências e Letras. n. 27, p. 61-90, 2000. 